\title{
Combinação de atributos naturais e antrópicos na definição do potencial de contaminação de aquíferos, sudeste do Brasil
}

\section{Combining natural and anthropic atributtes for aquifers contamination potential in southeast of Brazil}

\author{
Carlos Wilmer Costa ${ }^{1}$ \\ Reinaldo Lorandi ${ }^{2}$ \\ José Augusto Di Lollo ${ }^{3}$ \\ Vagner de Souza Serikawa ${ }^{\mathbb{D}}$
}

\begin{abstract}
Palavras-chave:
Água subterrânea

SIG

Análise multicritério

Atributos geoambientais
\end{abstract}

\section{Keywords:}

Groundwater

GIS

Multicriteria analysis

Geo-environmental attributes

\begin{abstract}
Resumo
Com o comprometimento da disponibilidade dos mananciais superficiais e o uso intenso dos mananciais subterrâneos para abastecimento, as unidades aquíferas estão cada dia mais expostas a riscos de contaminação. Diante disso, combinar atributos naturais às influências antrópicas é uma estratégia adequada para a avaliação potencial de contaminação de aquíferos. O trabalho apresenta cartas de potencial de contaminação de aquíferos na bacia hidrográfica do Rio Claro $\left(251,91 \mathrm{~km}^{2}\right.$, Santa Rita do Passa Quatro, SP) em escala 1:50.000, considerando as unidades aquíferas presentes, informações de geologia de superfície, materiais inconsolidados e declividade dos terrenos; combinados com uso e cobertura da terra, via análise multicritério em ambiente SIG. As classes de potencial "alto" e "muito alto" (46,1\% em 1994 e 48,6\% em 2014) foram as mais representativas na área. Os potenciais de contaminação obtidos expressaram claramente a importância dos atributos geológicos na área. As mudanças de uso e cobertura da terra identificadas no período foram determinantes para que o potencial de contaminação dos aquíferos aumentasse consideravelmente. A adoção de medidas de controle do uso/cobertura da terra e melhorias no manejo do solo são alternativas para a proteção das águas subterrâneas nesta bacia hidrográfica
\end{abstract}

\begin{abstract}
The compromise of surface water resources' quantity and quality, as well as the extensive use of groundwater, exposes aquifers to contamination risks. Considering this, combine natural and manmade influences is a proper strategy for potential aquifer contamination evaluation. This article presents charts of aquifer contamination potential in Rio Claro watershed $\left(251,91 \mathrm{~km}^{2}\right.$, in Santa Rita do Passa Quatro, SP) at 1:50,000 scale, taking in account aquifer units, surface geology units, soil and steepness information; operated using multicriteria analysis. The
\end{abstract}

\footnotetext{
${ }^{1}$ Universidade Federal do Rio Grande do Norte - UFRN, Departamento de Engenharia Civil e Ambiental, Natal, Rio Grande do Norte, Brazil. carloswilmercosta@gmail.com

2 Universidade Federal de São Carlos - UfSCar, Departamento de Engenharia Civil, São Carlos, São Paulo, Brazil. lorandir@gmail.com

3 Universidade Estadual Paulista - UNESP, Departamento de Engenharia Civil, Ilha Solteira, São Paulo, Brazil. jose.lollo@unesp.br

${ }_{4}^{4}$ Universidade Federal de São Carlos - UfSCar, Departamento de Engenharia Civil, São Carlos, São Paulo, Brazil. eng.urb.vagner@gmail.com
} 
classes "Very high" and "High potential" where the most representative classes of contamination potential in the watershed (performing 46.1\% in 1994 and $48.6 \%$ in 2014). Obtained contamination potential expressed geological attributes influence in the area. Land use / land cover changes were determinant for higher potential maintenance with time. Adoption of land use / land cover control measures and improvements in tillage management are alternatives for the groundwater protection in this watershed.

\section{INTRODUÇÃO}

A água subterrânea é a principal fonte de suprimento de água doce no mundo (MACHIWAL et al., 2018). No entanto, o uso intensivo e indiscriminado, tem ocasionado impactos diversificados na qualidade $e$ quantidade destes (FOSTER et al., 2013; RAVENGA, 2005; SCHEWE et al., 2014). Em escala global, estima-se que $20 \%$ dos aquíferos são excessivamente explorados (MILLENNIUM ECOSYSTEM ASSESSMENT, 2005; WHO, 2008; WWAP, 2015).

As principais fontes de degradação estão relacionadas à urbanização (ALLOUCHE et al., 2017) e a diversificação das atividades agrícolas, industriais, químicas, de petróleo e de mineração (BORCHARDT et al., 2003; JOHANSSON; HIRATA, 2004; MORAN et al., 2005; GANDY et al., 2007; OSENBRUCK et al., 2007; IRITANI et al., 2013; KHOSRAVI et al., 2018), as quais impulsionam a descarga de efluentes contaminados. Para Varnier e Hirata (2002) e Mahvi et al. (2005), o Nitrato derivado da agricultura e de áreas urbanizadas com problemas de infraestrutura de saneamento (POWELL et al., 2003), é o contaminante que mais afeta negativamente os aquíferos em escala global.

Aliado a este cenário, Tundisi et al. (2008) destaca a falta de gestão e de governabilidade desses recursos e o comprometimento da vegetação nativa de uma bacia hidrográfica (TUNDISI; MATSUMURA-TUNDISI, 2010), a qual aumenta significativamente os custos do tratamento da água para abastecimento público. Para Attanasio et al. (2013), Schilling e Jacobson (2014), Tanaka et al. (2016), Tromboni e Dodds (2017), Maello et al. (2018), Valera et al. (2019) e Guidotti et al. (2020), a falta e/ou redução da vegetação ripária representa mais danos à qualidade dos recursos hídricos do que a ausência de vegetação no restante da bacia hidrográfica.

Assim, a investigação da contaminação dos recursos hídricos subterrâneos tem forte ligação com as atividades agroindustriais e urbanas e tem se mostrado ferramenta adequada à adoção de medidas técnicas de gerenciamento hídrico (FOSTER et al., 2013) e de gestão do uso da terra (COSTA et al., 2019). Muitos compostos resultantes destas atividades são transformados em outros materiais e inseridos no ciclo hidrológico por processos naturais e antrópicos, modificando as características hidrogeoquímicas do sistema.

A avaliação da vulnerabilidade das águas subterrâneas tornou-se um importante tema de pesquisa no campo das geociências (GORELICK; ZHENG, 2015; WACHNIEW et al., 2016). No entanto, no Brasil, a compreensão deste tema é recente e restrita, uma vez que o usuário desse recurso, particular ou governamental, ainda desconhece sua importância e ignora as graves consequências de sua contaminação (LOURENCETTI et al., 2007).

Surge, então, a necessidade de elaboração de modelos de análise ambiental abrangentes que busquem compreender possíveis riscos de contaminação dos recursos hídricos subterrâneos pelo aporte de resíduos provenientes de diversas atividades humanas (CANCADO et al., 2008; TAVANTI et al., 2009; MORAES et al., 2011; IRITANI et al., 2013; MENEZES et al., 2014; COSTA et al., 2015b). Mundialmente, entre os métodos mais empregados destaca-se o DRASTIC (ALLER et al., 1987) e o GOD (FOSTER, 1987). No Brasil, a análise multicritério envolvendo matrizes de decisão e sobreposição de planos de informação em ambiente SIG têm alcançado resultados adequados além de um baixo custo (MARANGON et al., 2017; PIGA et al., 2017; COSTA et al., 2019).

Considerando as atividades humanas existentes na Bacia do Rio Claro (parcela significativa das áreas urbanas de Santa Rita do Passa Quatro e de Santa Cruz da Estrela; associada à cultura canavieira), são esperadas fontes de contaminação orgânicas, especialmente efluentes de esgotos domésticos e insumos agrícolas e de fertirrigação (LORANDI; LOLLO, 2016). Neste contexto, a partir da combinação de atributos do meio físico, biótico e antrópico, em ambiente SIG, e tendo como base investigações preliminares (LORANDI et al., 
2014), o presente estudo caracterizou o potencial de contaminação dos aquíferos na bacia do Rio Claro.

\section{LOCALIZAÇÃO E CARACTERIZAÇÃO GEOAMBIENTAL DA ÁREA DE ESTUDO}

A bacia hidrográfica do rio Mogi Guaçu, denominada Unidade de Gerenciamento de Recursos Hídricos 09 (UGRHI 09) no Estado de São Paulo está inserida na bacia hidrográfica do Rio Grande, região nordeste do Estado. Uma das sub-bacias dessa UGRHI é a do Rio Claro, que está toda inserida no compartimento Médio do Mogi Superior.

Com base em mapas na escala 1:2.500.000 (FEITOSA, 2008), essa bacia localiza-se na Província Hidrogeológica da Bacia do Paraná, caracterizada por apresentar muita alta a média favorabilidade hidrogeológica. Numa versão mais detalhada (escala 1:1.000.000), verifica-se que a bacia encontra-se territorialmente envolvida pelos aquíferos Guarani (aflorante) e Serra Geral Intrusivas (DAEE-IG-IPT-CPRM, 2005).

Em escala 1:50.000, verifica-se que na área de estudo ocorrem seis unidades aquíferas (LORANDI et al., 2014) (Figura 1).

Figura 1 - Localização geográfica e unidades aquíferas da bacia hidrográfica do rio Claro.
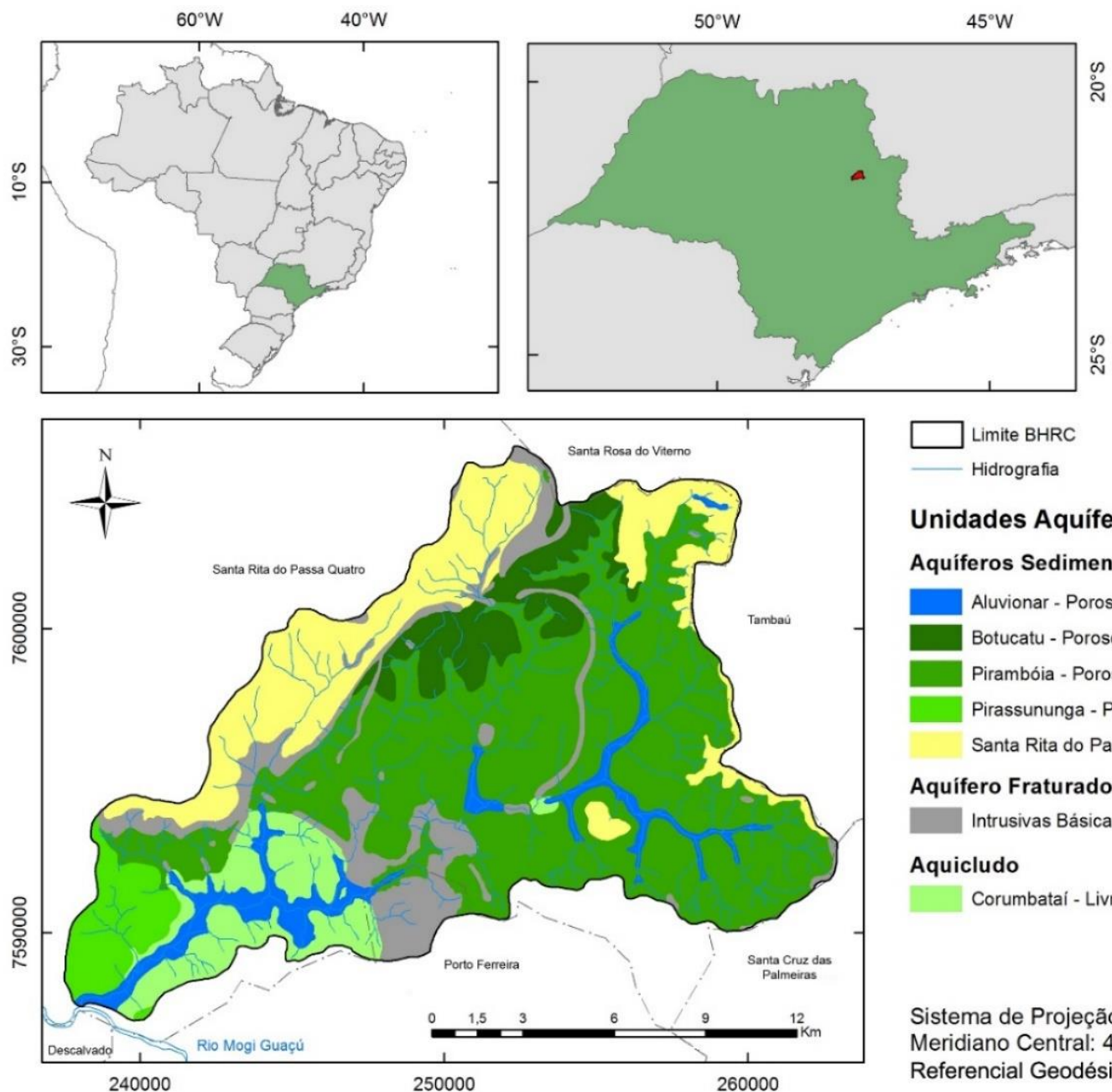

\section{Unidades Aquíferas}

Aquíferos Sedimentares

Aluvionar - Poroso; Livre

Botucatu - Poroso; Parcialmente Livre

Pirambóia - Poroso; Parcialmente Livre

Pirassununga - Poroso; Livre

Santa Rita do Passa Quatro - Poroso; Livre

Aquífero Fraturado

Intrusivas Básica - Fraturado; Semi-confinado

\section{Aquicludo}

Corumbataí - Livre

Sistema de Projeção UTM

Meridiano Central: $45^{\circ}$

Referencial Geodésico: SIRGAS2000

Fonte: Instituto Geológico (IG) (1981a, 1981b, e 1984). Org.: do Autor, 2020.

Segundo o IG (1981a, 1981b, 1984) e Melo (1995), a área estudada apresenta as seguintes formações geológicas (Tabela 1). 
Tabela 1. Unidades litoestratigráficas reconhecidas na área de estudo.

\begin{tabular}{|c|c|c|}
\hline Unidade & $\begin{array}{c}\text { Era } \\
\text { Período }\end{array}$ & Descrição \\
\hline $\begin{array}{c}\text { Depósitos } \\
\text { Aluvionares }\end{array}$ & $\begin{array}{c}\text { Cenozóica } \\
\text { Holoceno }\end{array}$ & $\begin{array}{l}\text { São representados por amplas planícies que ocorrem ao longo dos } \\
\text { fundos de vale do Rio Claro e afluentes principais. São constituídas } \\
\text { por sedimentos aluvionares e coluvionares de textura arenosa devido } \\
\text { à contribuição das litologias adjacentes. }\end{array}$ \\
\hline $\begin{array}{l}\text { Formação } \\
\text { Piraçununga }\end{array}$ & $\begin{array}{l}\text { Cenozóica } \\
\text { Terciário }\end{array}$ & $\begin{array}{l}\text { É composta por sedimentos areno-argilosos de cor castanhos claros } \\
\text { sem estruturas sedimentares muito pobremente selecionados. Na } \\
\text { base, geralmente apresenta linha de seixos ou cascalheira, com } \\
\text { seixos de quartzo e quartzito e fragmentos de limonita, sobrepostos } \\
\text { de forma discordante sobre a Formação Corumbataí. }\end{array}$ \\
\hline $\begin{array}{l}\text { Formação } \\
\text { Santa Rita do } \\
\text { Passa Quatro }\end{array}$ & $\begin{array}{l}\text { Cenozóica } \\
\text { Terciário }\end{array}$ & $\begin{array}{l}\text { Constituem-se de areias em matriz argilosa, sem estruturas } \\
\text { sedimentares com cascalheira basal de seixos predominantemente } \\
\text { de quartzo. Na área estes sedimentos têm coloração marrom, são } \\
\text { muito friáveis e apresentam grânulos de quartzo dispersos em toda } \\
\text { a espessura, esta, varia de poucos cm até alguns metros com apmpla } \\
\text { distribuição horizontal (MASSOLI, 1981). }\end{array}$ \\
\hline
\end{tabular}

São regionalmente constituídos de soleiras e diques de magmatitos Formação básicos, de textura fanerítica e coloração cinza a preta, apresentando Serra Geral Mesozóica intensamente fraturados e aspecto denso. Em fotografias aéreas, Cretáceo apresentam tonalidades cinza escuras, pendentes abruptas e distribuição preferencial ao longo de interflúvios.

\begin{tabular}{|c|c|c|}
\hline $\begin{array}{l}\text { Formação } \\
\text { Botucatu }\end{array}$ & $\begin{array}{c}\text { Mesozóica } \\
\text { Jura/Cretác } \\
\text { eo }\end{array}$ & $\begin{array}{l}\text { Constituída predominantemente por arenitos eólicos atribuídos a } \\
\text { depósitos em ambiente desértico, com granulação fina a média, } \\
\text { partículas bem arredondadas e composição essencialmente } \\
\text { quartzosa ( } 80 \% \text { ), a espessura varia entre } 20 \text { e } 280 \text { metros. Apresenta } \\
\text { grande quantidade de poros interconectados e uma elevada } \\
\text { capacidade de armazenar e fornecer água. }\end{array}$ \\
\hline
\end{tabular}

\begin{tabular}{ccl}
\hline Formação & $\begin{array}{l}\text { Composta por arenitos fluviais esbranquiçados, amarelados e róseos, } \\
\text { Pirambóia }\end{array}$ & $\begin{array}{l}\text { médios a finos, às vezes bastantes argilosos, em função de } \\
\text { posicionamento estratigráfico. Em fotografias aéreas, apresentam } \\
\text { tonalidades cinza claro a branca, com sistema de drenagem pouco } \\
\text { desenvolvido, com padrão dendrítico. }\end{array}$ \\
\hline $\begin{array}{c}\text { Formação } \\
\text { Corumbataí }\end{array}$ & $\begin{array}{l}\text { Paleozóica } \\
\text { Permiano }\end{array}$ & $\begin{array}{l}\text { Composta, regionalmente, por folhelhos variegados, estando } \\
\text { posicionada entre as formações Irati (inferior) e Pirambóia } \\
\text { (superior). Em fotografias aéreas, estampa tonalidades cinza escuras } \\
\text { e alta densidade de drenagem com padrão penado. }\end{array}$ \\
\hline
\end{tabular}

Org.: do Autor, 2020.

De acordo com Lorandi e Lollo (2016), as unidades de materiais inconsolidados identificadas na bacia têm suas principais características geotécnicas apresentadas na Tabela 2.

Pela divisão geomorfológica do Estado de São Paulo (ROSS; MOROZ, 1997), a bacia está inserida na Unidade Morfoestrutural da Bacia Sedimentar do Paraná, abrangendo parcialmente a Unidade Morfoescultural Depressão Periférica Paulista a qual é esculpida quase que totalmente nos sedimentos paleozóicos e mesozóicos. Em nível taxonômico inferior, é representada pela unidade morfológica denominada Depressão de Mogi Guaçu, a qual é constituída por colinas de topos tabulares amplos, com vales entalhados até $20 \mathrm{~m}$, e dimensão interfluvial entre 1.750 e $3.750 \mathrm{~m}$. As cotas altimétricas predominantes estão entre 500 e $650 \mathrm{~m}$ e as declividades predominantes entre 5 e $10 \%$. 
Tabela 2 - Caracterização geotécnica dos materiais inconsolidados.

\begin{tabular}{|c|c|c|c|c|c|c|}
\hline \multirow{2}{*}{$\begin{array}{c}\text { Materiais } \\
\text { Inconsolidados }\end{array}$} & \multirow{2}{*}{$\begin{array}{l}\text { Área } \\
\left(\mathrm{km}^{2}\right)\end{array}$} & \multirow{2}{*}{$\begin{array}{l}\text { Espessura } \\
\quad(\mathrm{m})\end{array}$} & \multicolumn{3}{|c|}{ Granulometria (\%)* } & \multirow{2}{*}{$\begin{array}{l}\text { Coeficiente de } \\
\text { permeabilidade } \\
(\mathrm{cm} / \mathrm{s})\end{array}$} \\
\hline & & & $\mathrm{Ag}$ & $\mathrm{S}$ & $\mathrm{Ar}$ & \\
\hline Quaternário & 15,87 & $<2,2-5$ & 5 & 4 & 91 & $6,110^{-3}$ \\
\hline $\begin{array}{c}\text { Res. Santa Rita do P. } \\
\text { Quatro }\end{array}$ & 45,72 & $>5$ & 14 & 8 & 78 & $3,710^{-2}$ \\
\hline Res. Piraçununga & 11,38 & $>5$ & 28 & 7 & 65 & $4,210^{-3}$ \\
\hline Res. Botucatu & 17,65 & $<2,>5$ & 20 & 5 & 75 & $3,810^{-3}$ \\
\hline Res. Pirambóia & 11,38 & $<2,>5$ & 24 & 6 & 70 & $7,110^{-3}$ \\
\hline $\begin{array}{c}\text { Res. Magmatitos } \\
\text { Básicos }\end{array}$ & 26,48 & $<2,2-5,>5$ & 47 & $\begin{array}{l}1 \\
7\end{array}$ & 36 & $4,910^{-4}$ \\
\hline Res. Corumbataí & 19,65 & $<2$ & 77 & 9 & 14 & $4,110^{-4}$ \\
\hline
\end{tabular}

*Ag = Argila, $\mathrm{S}=$ Silte, Ar. = Areia. Org.: do Autor, 2020.

De acordo com o sistema de Köppen (1948), o clima é classificado como sendo do tipo Cwa, isto é, de inverno seco (estação seca), em que a temperatura média do mês mais frio é inferior a $18^{\circ} \mathrm{C}$ e a do mês mais quente ultrapassa $22^{\circ} \mathrm{C}$ (estação chuvosa). A cobertura florestal é composta pela Mata Atlântica e pelo Cerrado, com predomínio da formação atlântica da Floresta Estacional Semidecidual (SÃO PAULO, 2009).

\section{MATERIAIS E MÉTODO}

A delimitação da bacia do Rio Claro (limitada pelas coordenadas extremas $47^{\circ} 17^{\prime} 35,13^{\prime \prime} \mathrm{W}$ e $47^{\circ} 32^{\prime} 8,9^{\prime \prime} \mathrm{W} ; 2^{\circ} 37^{\prime} 46,7^{\prime \prime} \mathrm{S}$ e $21^{\circ} 48^{\prime} 13^{\prime \prime} \mathrm{S}$ ), foi realizada a partir da digitalização das folhas topográficas (IBGE, 1972). Os planos de informação foram georreferenciados na zona 23S, adotando o referencial geodésico SIRGAS2000 (IBGE, 2005) e projeção Universal Transversa de Mercator (UTM). Para o tratamento espacial dos dados, foram utilizados os softwares ArcGIS ${ }^{\circledR} 10.2$ (ESRI, 2013) e Idrisi Selva.

Para a montagem do banco de dados com informações geográficas foram utilizados os seguintes documentos cartográficos, todos na escala 1:50.000: mapa das formações geológicas de superfície IG (1981a, 1981b, 1984), o mapa de materiais inconsolidados, carta das classes de declividade e a carta de unidades aquíferas (LORANDI et al., 2014).

Para a elaboração dos mapas de uso e cobertura da terra, por meio de classificação supervisionada, foram utilizadas imagens do satélite LANDSAT 5 de 31/05/1994 (composição colorida RGB das bandas 5, 4 e 3), resolução espacial de 30 metros e imagens LANDSAT 8 de 22/05/2014 (composição colorida RGB das bandas 6,5 e 4), resolução espacial de 30 metros, com a fusão da banda pancromática 8 de 15 metros (USGS, 2016).

Na Figura 2, são mostradas a distribuição espacial dos seguintes atributos: materiais inconsolidados, declividade e uso e cobertura da terra (1994 e 2014). 
Figura 2 - Atributos utilizados no processo de análise multicritério.

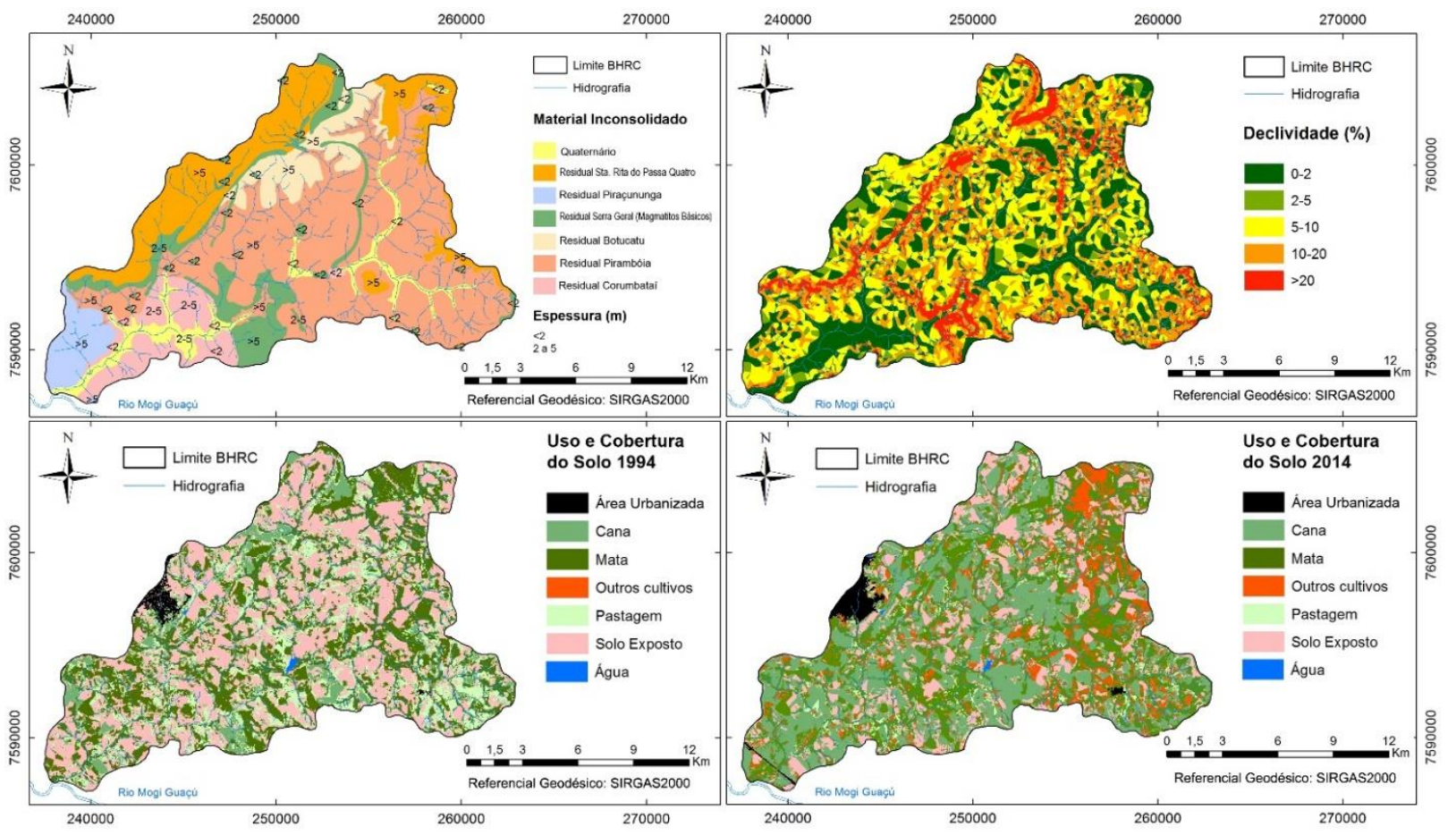

Org.: do Autor, 2020.

Para atingir o objetivo proposto, utilizou-se uma estratégia de análise multicritério com o uso de matrizes de decisão e a avaliação dos critérios por equipe multidisciplinar. A análise multicritério é caracterizada pela sobreposição lógica de atributos do meio físico e antrópicos em ambiente SIG.

Deste processo, chegou-se a análise dos vários critérios, que levaram a verificação do potencial de contaminação dos aquíferos durante 20 anos (1994 e 2014), e cenários descritivos provenientes das alterações no uso da terra ocorridas neste período. Na Figura 3, está ilustrado o método utilizado, contendo, como exemplo a primeira sobreposição (Unidades Aquíferas $\mathrm{x}$ Materiais Inconsolidados).

A álgebra de mapas, relativa ao uso dos pesos definidos, foi fundamentada na metodologia descrita por Costa et al. (2019), que consistiu na integração de planos de informação em ambiente SIG, por meio de matrizes de decisão, utilizando a ferramenta Weighted Sum do software ArcGIS ${ }^{\circledR} 10.2$ (ESRI, 2013). Os cruzamentos dos atributos geoambientais foram realizados dois a dois, sendo que os pesos, com valores variando de 1 a 5 (Muito Baixo e Muito Alto), foram estabelecidos a partir da experiência e expertise dos pesquisadores da área de geociências, conforme as Tabelas 3 a 5 .

Com o intuito de avaliar as mudanças ocorridas no uso e cobertura da terra, foi utilizado o módulo Land Change Modeler (EASTMAN, 2012) do software Idrisi Selva a partir das classificações supervisionadas de 1994 a 2014. As técnicas utilizadas para criação de cenários considerando dados históricos foram baseadas nos trabalhos de Oñate-Valdivieso e Sendra (2010) e Huong e Pathirana (2013). 
Figura 3 - Fluxograma do processo de análise multicritério.

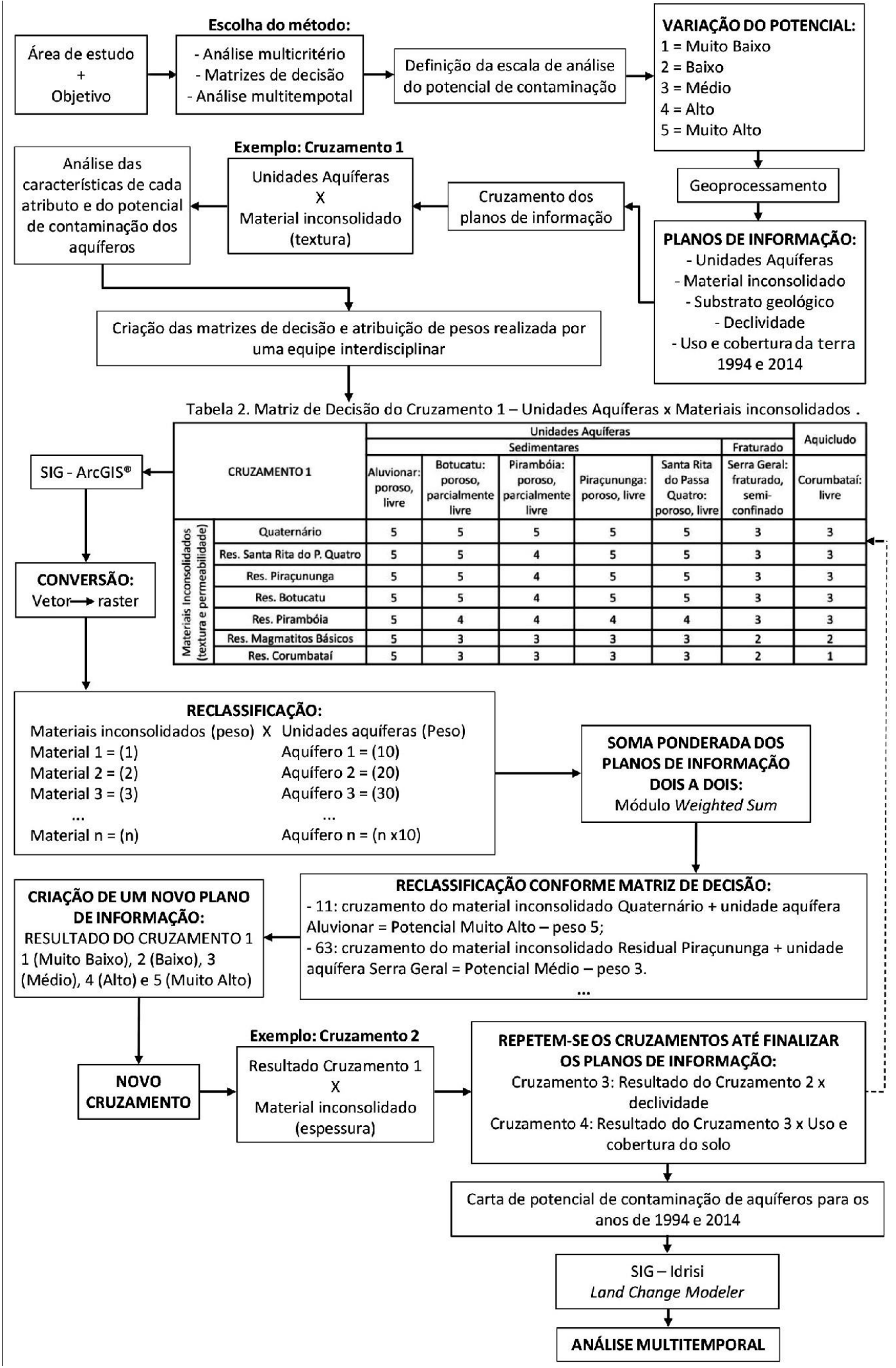

Org.: do Autor, 2020. 
Tabela 3 - Matriz de decisão do cruzamento 2 - Resultado 1 x Materiais Inconsolidados (espessura).

\begin{tabular}{|c|c|c|c|c|}
\hline \multirow{2}{*}{\multicolumn{2}{|c|}{ CRUZAMENTO 2}} & \multicolumn{3}{|c|}{$\begin{array}{c}\text { Materiais inconsolidados } \\
\text { (espessura) }\end{array}$} \\
\hline & & $(>5 \mathrm{~m})$ & $(2-5 \mathrm{~m})$ & $(<2 \mathrm{~m})$ \\
\hline \multirow{5}{*}{ 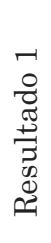 } & Muito Baixo - & 1 & 2 & 3 \\
\hline & Baixo - 2 & 1 & 2 & 3 \\
\hline & Médio - 3 & 2 & 3 & 4 \\
\hline & Alto - 4 & 3 & 4 & 5 \\
\hline & Muito Alto - 5 & 4 & 5 & 5 \\
\hline
\end{tabular}

Tabela 4 - Matriz de decisão do cruzamento 3 - Resultado 2 x Declividades.

\begin{tabular}{|c|c|c|c|c|c|c|}
\hline \multirow{2}{*}{\multicolumn{2}{|c|}{ CRUZAMENTO 3}} & \multicolumn{5}{|c|}{ Declividades } \\
\hline & & $>20 \%$ & $10-20 \%$ & $5-10 \%$ & $2-5 \%$ & $0-2 \%$ \\
\hline \multirow{5}{*}{ 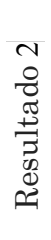 } & Muito Baixo - 1 & 1 & 1 & 1 & 2 & 3 \\
\hline & Baixo - 2 & 1 & 1 & 2 & 3 & 4 \\
\hline & Médio - 3 & 2 & 2 & 3 & 4 & 4 \\
\hline & Alto - 4 & 3 & 4 & 4 & 5 & 5 \\
\hline & Muito Alto - 5 & 3 & 4 & 5 & 5 & 5 \\
\hline
\end{tabular}

Tabela 5 - Matriz de decisão do cruzamento 4 - Resultado 3 x Uso e cobertura da terra.

\begin{tabular}{|c|c|c|c|c|c|c|c|c|}
\hline \multirow{2}{*}{\multicolumn{2}{|c|}{ CRUZAMENTO 4}} & \multicolumn{7}{|c|}{ Uso e cobertura da terra } \\
\hline & & $\begin{array}{l}\text { Cana-de- } \\
\text { açúcar }\end{array}$ & $\begin{array}{l}\text { Corpos } \\
\text { hídricos }\end{array}$ & $\begin{array}{l}\text { Outros } \\
\text { cultivos* }\end{array}$ & Pastagem & $\begin{array}{c}\text { Solo } \\
\text { exposto }\end{array}$ & $\begin{array}{l}\text { Vegetação } \\
\text { nativa }\end{array}$ & $\begin{array}{c}\text { Área } \\
\text { urbanizada }\end{array}$ \\
\hline \multirow{5}{*}{ 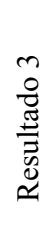 } & Muito Baixo - & 2 & 3 & 2 & 1 & 2 & 1 & 2 \\
\hline & Baixo - 2 & 3 & 3 & 2 & 2 & 3 & 1 & 3 \\
\hline & Médio - 3 & 4 & 4 & 3 & 3 & 4 & 2 & 4 \\
\hline & Alto - 4 & 5 & 5 & 4 & 4 & 5 & 2 & 5 \\
\hline & Muito Alto - 5 & 5 & 5 & 5 & 5 & 5 & 3 & 5 \\
\hline
\end{tabular}

*Citrus, Café, Eucalipto. Org.: do Autor, 2020.

\section{RESULTADOS E ANÁLISES}

Os resultados com os cinco níveis hierárquicos de potencial de contaminação da água subterrânea, considerando o uso e cobertura da terra em 1994, são exibidos na Figura 4.

Em conjunto, as classes de potencial de contaminação alto e muito alto representam $46,1 \%$ da área da bacia. O percentual tão significativo dessas classes de potenciais alto e muito alto é reflexo especialmente do ambiente geológico, que apresenta na maior parte de sua área unidades aquíferas porosas, livres e parcialmente livres, em unidades litoestratigráficas constituídas por arenitos.

A classe mais frequente em termos espaciais $(30,7 \%)$ é a de potencial muito alto de contaminação, cujas áreas se concentram nas porções NW e SW da bacia.

Secundariamente, as características das unidades aquíferas tiveram grande influência na identificação de classes de potencial alto e muito alto pelo fato de serem recobertas por materiais inconsolidados de textura arenosa, em áreas de baixa declividade do terreno associada aos usos do solo que favorecem a infiltração (especialmente agrícola). 
Figura 4 - Potencial de contaminação de unidades aquíferas em 1994.

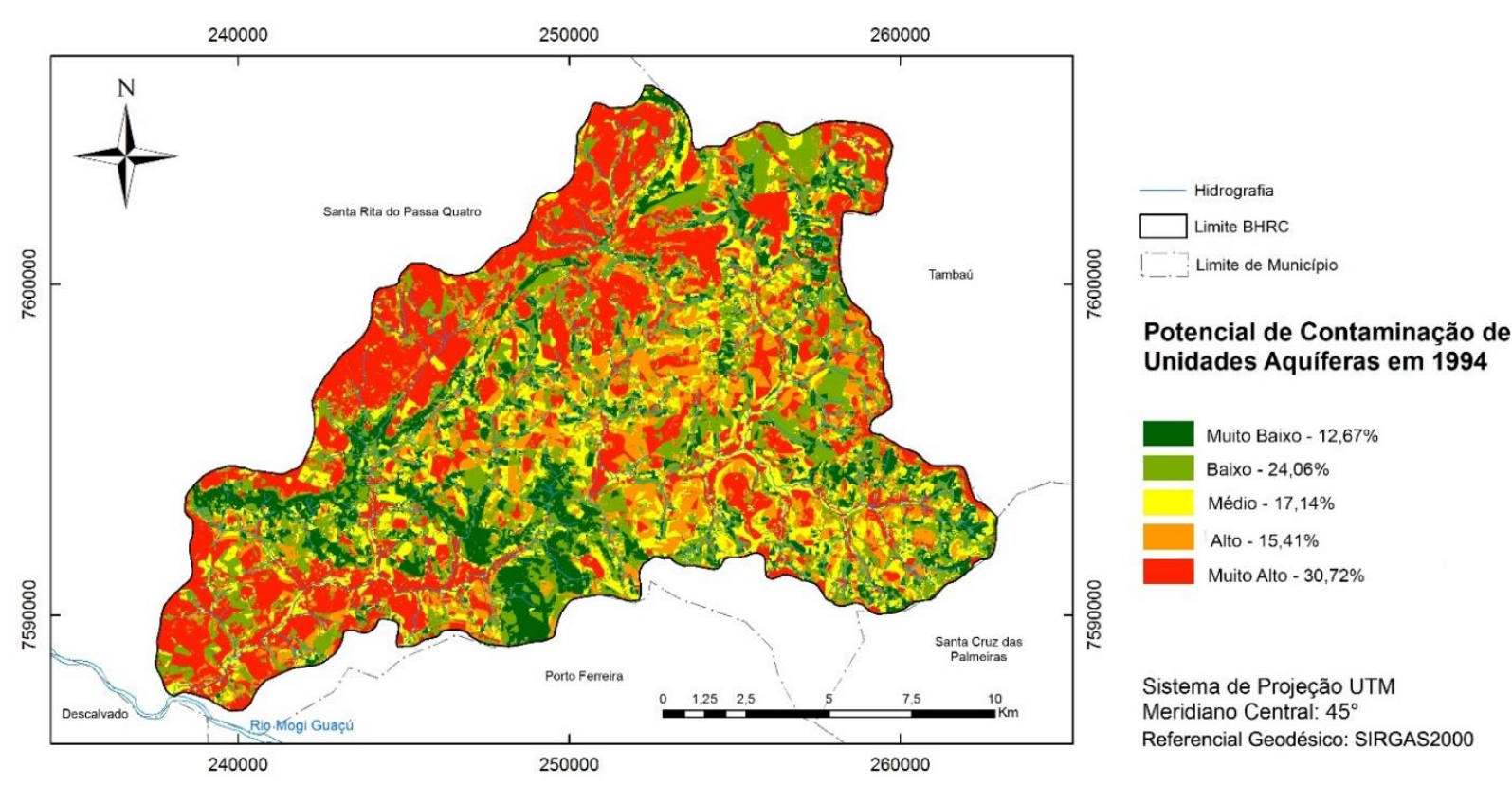

Org.: do Autor, 2020.

A classe potencial alto representa $15,4 \%$ e se encontra dispersa por toda a bacia. Sua definição, se deve especialmente à combinação de materiais inconsolidados arenosos recobrindo aquíferos porosos, parcialmente livres, em áreas de solo exposto e declividades inferiores a 10\%.

A classe designada médio potencial $(17,1 \%)$, que também ocorre de forma dispersa na área, se deve principalmente à combinação de baixa declividade com perfis de materiais inconsolidados de pequena espessura e solo exposto, o que faz com que mesmo áreas de ocorrência de unidades aquíferas semiconfinadas apresentem médio potencial.

As áreas que apresentam potencial de contaminação baixo representam a segunda classe mais frequente $(24,0 \%)$, sendo que sua identificação está associada às áreas de unidades aquíferas semi-confinadas em relevos de alta declividade, perfis de alteração com maiores espessuras e em áreas geralmente ocupadas por matas.

Finalmente, as áreas classificadas como de potencial muito baixo $(12,7 \%)$ se relacionam particularmente às áreas de maior declividade e ocorrência de matas.
A classificação dos potencias de contaminação em 2014, ilustra como as mudanças em padrões de uso e cobertura da terra que ocorreram na área podem influenciar a vulnerabilidade das unidades aquíferas (Figura 5).

Em 2014, a classe de potencial de contaminação muito alto representa o maior percentual da área (31,9\%), que somado ao da classe de potencial alto, representam $48,6 \%$ da área da bacia.

Se comparado com o ano de 1994, as áreas classificadas como potencial muito alto permanecem praticamente a mesma, ocupando áreas nas regiões NW e SW, devendo-se aos mesmos fatores: unidades aquíferas porosas e livres, recobertas por materiais inconsolidados de textura arenosa em áreas de baixa declividade e uso agrícola, em fase de cultivo ou de preparo da terra para plantio.

De forma análoga, a classe de potencial alto $(16,7 \%)$ reúne unidades aquíferas livres e parcialmente livres, com cobertura de materiais inconsolidados arenosos com espessura pequena a média e uso agrícola. Sua distribuição espacial ocorre de maneira dispersa pela bacia hidrográfica, sendo maior na região central. 
Figura 5 - Potencial de contaminação de unidades aquíferas em 2014.

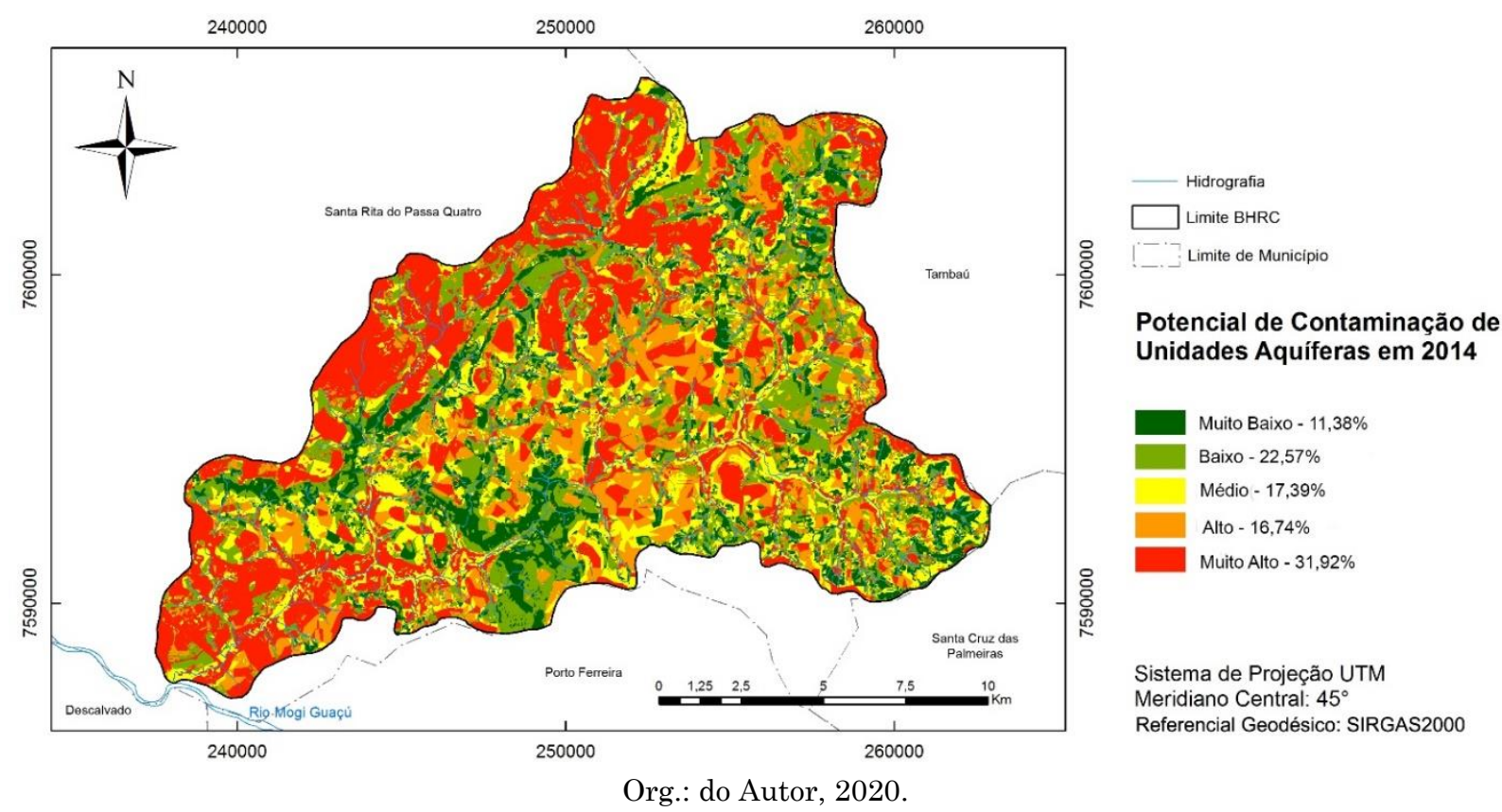

A classe de potencial de contaminação médio $(17,4 \%)$ também ocorre de forma dispersa na bacia, concentrada nos fundos dos vales em função da vulnerabilidade do aquífero aluvionar (poroso e livre).

Os potenciais baixo e muito baixo $(22,6$ e $11,4 \%$, respectivamente) concentram-se nas porções mais elevadas do terreno, em área com declividades maiores que $10 \%$ nas unidades aquíferas denominadas Corumbataí e Intrusivas Básicas.

\section{Influência das mudanças de uso e cobertura da terra}

O uso e cobertura da terra pode refletir negativamente no potencial de contaminação das águas subterrâneas. Desta forma, a espacialização desta dinâmica é de fundamental importância para o melhor entendimento de como afetam diretamente os serviços ecossistêmicos, principalmente o aporte de água para o abastecimento, uso industrial e agrícola.

As cartas de uso e cobertura da terra elaboradas para as datas de 1994 e 2014 mostram um cenário comum à grande parte do interior paulista, em especial a substituição de áreas rurais de pastagem para culturas anuais, em particular a cana-de-açúcar.

Em 1994, as áreas urbanas representavam $1 \%$ da bacia, cana-de-açúcar $8 \%$, solo exposto
$38 \%$ e pastagens $19 \%$. O alto percentual de solo exposto ocorre em função do preparo para o cultivo e das áreas de pastagens com baixa densidade vegetal, principalmente em período de estiagem. O percentual de $33 \%$ coberto por matas em 1994 reflete o uso tipicamente pastoril na bacia com pastos naturais, sem remoção das coberturas vegetais arbóreas.

Em 2014, áreas urbanas passam a ocupar 5\% da bacia, cana-de-açúcar $34 \%$, solo exposto $13 \%$ e pastagens $4 \%$. É interessante notar que mesmo com o crescimento da parcela da bacia ocupada por cana-de-açúcar, o percentual de matas não apresentou redução significativa, fato relacionado à localização dessas coberturas arbóreas em áreas com declividades mais acentuadas ou em áreas de solos litólicos, pouco favorável para o plantio de cana-de-açúcar.

Considerando que os atributos físicos como a geologia, os materiais inconsolidados e declividade não passaram por mudanças significativas no período avaliado, o uso do Land Change Modeler, conforme descrito anteriormente, permitiu verificar a dinâmica das mudanças de uso e cobertura na área as quais estão intrinsecamente relacionadas com as mudanças do potencial de contaminação das águas subterrâneas para os anos de $1994-2014$. No mapa da Figura 6 é possível identificar mudanças importantes nas classes solo exposto e cana-de-açúcar. 
Figura 6 - Mudanças no uso e cobertura da terra (1994-2014).
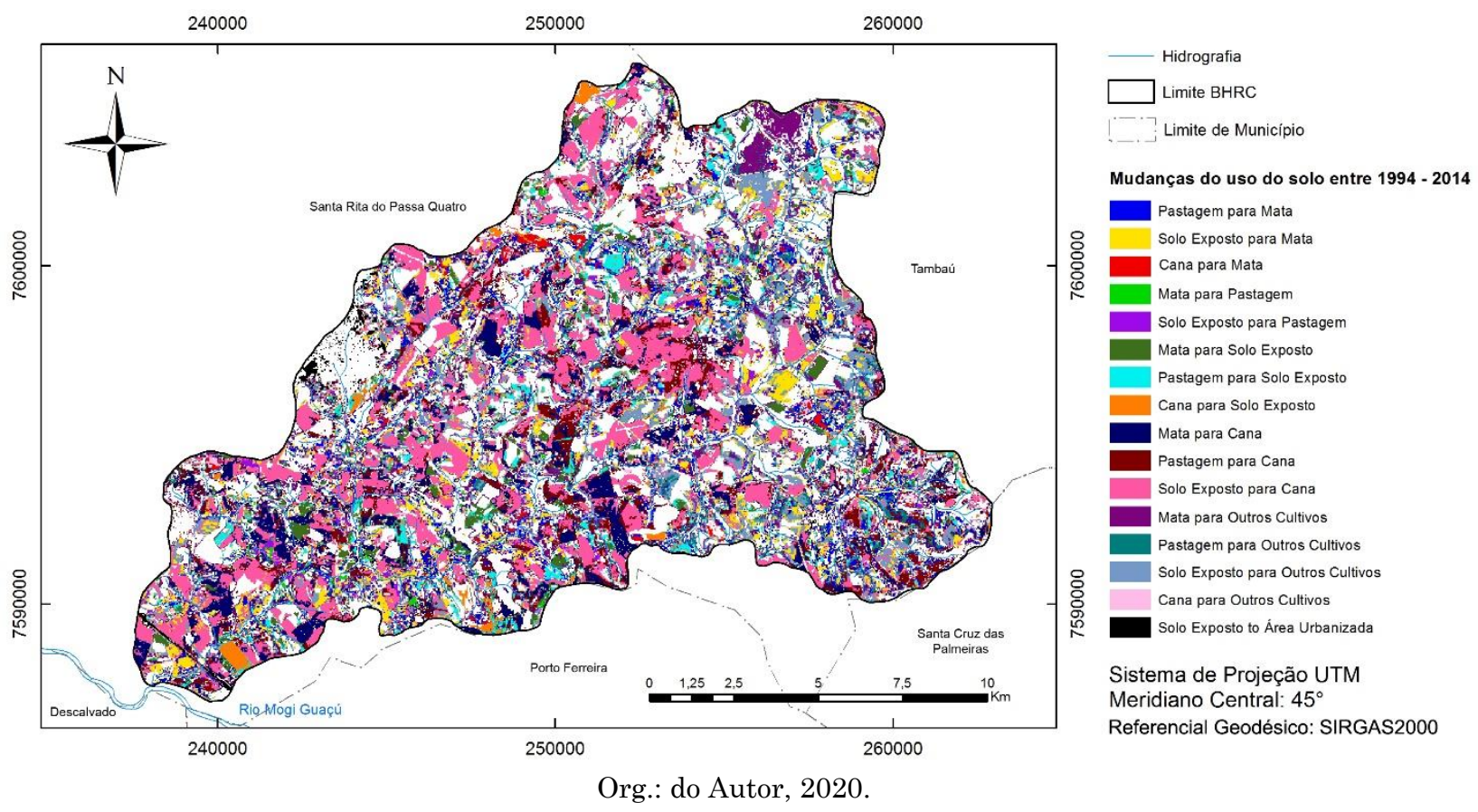

As persistências (áreas que não tiveram mudanças no uso e cobertura da terra) para as mesmas classes são apresentadas na Figura 7.

Neste caso, ficam evidentes as persistências nas classes mata, solo exposto, e cana-de-açúcar.

Figura 7 - Persistências de uso e cobertura da terra (1994-2014).

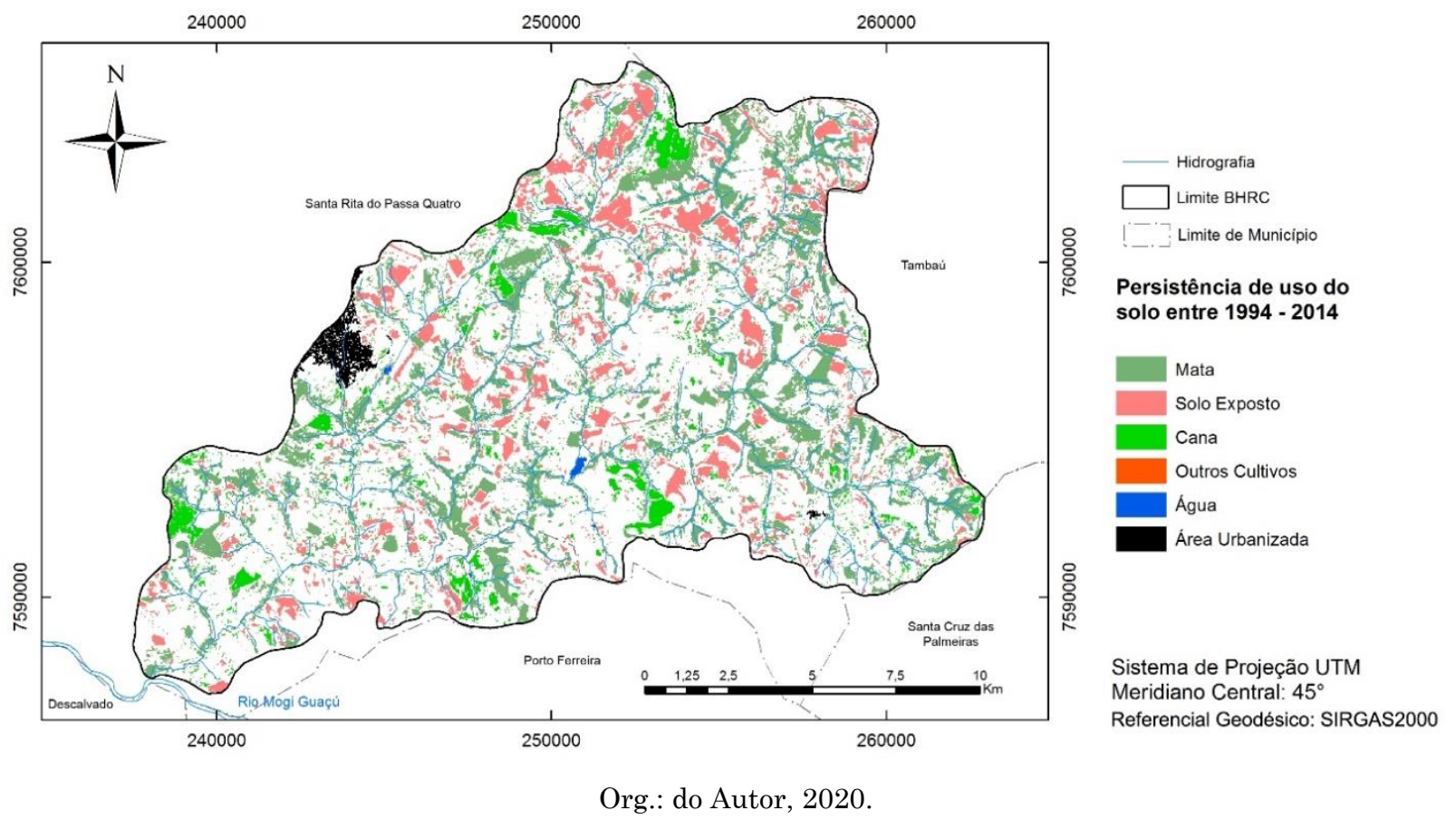

A Figura 8 apresenta os ganhos e perdas nas mudanças de uso e cobertura da terra entre 1994 e 2014. As persistências em parcelas da área classificadas como cana se justificam por se tratarem de propriedades que tradicionalmente apresentam tal cultivo. Por outro lado, as áreas que mostram persistência da classe solo exposto ocorrem em função do constante preparo das terras para receber a cana além de áreas com vegetação rarefeita, principalmente em época de estiagem. 
Figura 8 - Ganhos e perdas nas mudanças de uso e cobertura da terra entre 1994 e 2014 (A), mudanças no aumento da cana-de-açúcar (B), redução da classe solo exposto (C) e mudanças na redução da mata ciliar (D).

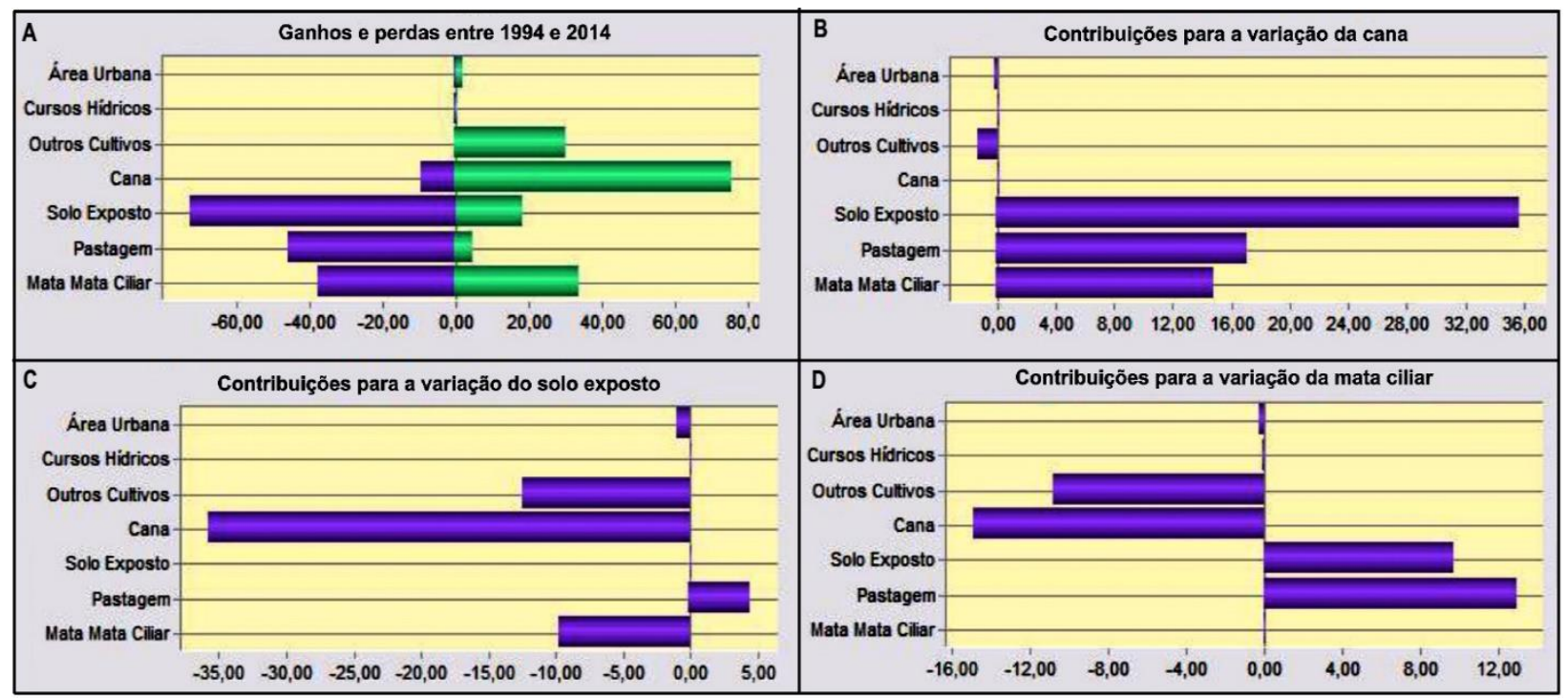

Org.: do Autor, 2020.

As mudanças mais notáveis (Figura 8a), detêm correspondência direta com o crescimento significativo da classe cana-de-açúcar e o surgimento da classe outros cultivos, com fortes reduções nas classes, solo exposto e pastagem, e pequena redução na classe mata.

Verifica-se também, que os aumentos na classe cana-de-açúcar se deram particularmente à custa de reduções nas classes solo exposto (35\%), pastagem (17\%) e mata (14\%) (Figura 8b); enquanto a redução na classe solo exposto resulta da expansão das áreas de cana e de outros cultivos (Figura 8c).

Nota-se ainda, que parcelas importantes da classe mata tiveram seu uso alterado para as classes cana e solo exposto (Figura 8d). Isso indica fiscalização ineficiente e falta de consciência. Salienta-se que essa substituição deve ser impedida de todas as formas. No entanto, o novo Código Florestal de 2012 (BRASIL, 2012) tornou essa proteção mais fragilizada, principalmente nas áreas de preservação permanente dos cursos d'água, que em grande parte, diminuíram de $30 \mathrm{~m}$ para $5 \mathrm{~m}$. No caso dos reservatórios, a diferença de altitude entre a cota máxima utilizada anteriormente (BRASIL, 1965) e a cota operacional utilizada atualmente, gerou perdas significativas de vegetação marginal, um bom exemplo é verificado no estudo de Rocha, Freitas e Casquim (2019) nas APPs hídricas de um manancial da Zona da Mata mineira. Os topos de morro praticamente acabaram pelo entendimento que a preservação deve iniciar a partir da "cota do ponto de sela mais próximo da elevação". Aqui, vale a pena ressaltar que foi um retrocesso ambiental sem precedentes. Por outro lado, a Lei da Mata Atlântica (BRASIL, 2006) deveria ser outra forma de impedir essa tendência negativa, no entanto, verifica-se pouca efetividade no cumprimento da lei.

Tendo em vista os levantamentos efetuados para a caracterização dos atributos do meio físico e as mudanças de uso e cobertura da terra identificadas na bacia, é possível relacionar tal conjunto de informações com a dinâmica observada, considerando ainda resultados obtidos por outros autores em bacias contíguas que apresentam o mesmo contexto geológico e geomorfológico.

Em termos regionais, é comum encontrar investigações (LOLLO, 1991; BROLLO, 1991; AGUIAR, 1995) que destacam a ocorrência na região de unidades de materiais inconsolidados residuais e retrabalhados de textura arenosa, com perfis de alteração espessos, e altas porosidades. Tais perfis de alteração, além de muito favoráveis à infiltração, ocorrem com maior frequência em topos de colinas com baixas declividades (usualmente menor que 5\%), contexto geológico característico de áreas de recarga nessa porção da Depressão Periférica.

Considerando o potencial de contaminação de aquíferos e sua relação com as unidades geoambientais, Costa et al. (2015b) estabeleceram a relação entre as unidades aquíferas com litologias clásticas e textura arenosa (Pirambóia, Botucatu e Tatuí) e os materiais inconsolidados residuais de textura arenosa delas derivados e altos potenciais de 
contaminação, em particular quando as condições de uso e cobertura da terra favorecem o aparecimento de fontes de contaminação. Análoga conjunção de fatores se repete na Bacia Hidrográfica do Rio Claro, em particular com relação à Unidade Aquífera Pirambóia.

\section{Estratégias de planejamento territorial e de proteção das águas subterrâneas}

No Brasil inexiste uma legislação específica diretamente voltada para a proteção de áreas de recarga de aquíferos, inclusive para a proteção das áreas de recarga do Aquífero Guarani, de importância regional e continental.

No Estado de São Paulo, o Decreto $n^{\circ}$ $32.955 / 91$ que regulamenta a Lei $\mathrm{n}^{\circ}$ 6.134/91, prevê que as áreas de recarga a serem protegidas serão "estabelecidas com base em estudos hidrogeológicos, ouvidos os municípios e demais organismos interessados". Tal Decreto também classifica como "Área de Proteção Máxima: compreendendo, no todo ou em parte, zonas de recarga de aquíferos altamente vulneráveis à poluição e que se constituam em depósitos de águas essenciais para abastecimento público" (MORAES et al., 2016).

$\mathrm{Na}$ ausência de uma lei federal ou estadual que defina as áreas de proteção para a recarga, os Planos Diretores dos municípios localizados principalmente nos afloramentos das Formações Botucatu e Pirambóia, que constituem o Aquífero Guarani, assumem um papel importante e deveriam complementar tais leis (COSTA et al., 2019).

No entanto, conforme também foi verificado por Moraes et al. (2016), o Plano Diretor de Santa Rita do Passa Quatro (SANTA RITA DO PASSA QUATRO, 2006) não contempla um zoneamento específico para as áreas altamente vulneráveis com relação à contaminação das águas subterrâneas (Botucatu e Pirambóia), as quais também são de recarga direta do Aquífero Guarani. Para essas áreas, a definição de unidades de proteção do patrimônio natural parece ser a alternativa mais viável para proteger as águas subterrâneas.

Diante da vasta alteração nas condições naturais identificada na bacia do Rio Claro e da falta de leis específicas, compete aos técnicos da área propor estratégias de gestão territorial que atenuem os impactos negativos das atividades humanas sobre os recursos hídricos subterrâneos no manancial:

- Devem ser incluídas na legislação municipal, leis em escala mais refinada, de modo a planejar o uso do solo especificamente nas áreas de afloramento dos aquíferos Aluvionar,
Botucatu e Pirambóia. Nessas áreas, foram constatados os maiores potenciais de contaminação, concomitantemente, é onde a capacidade de infiltração das águas pluviais é intensificada.

Prioridade deve ser dada às práticas de revegetação nos topos de morros, locais que, quando preservados com vegetação nativa, favorecem a infiltração da água e recarga (ROCHA, 2019).

Monitorar in situ, o uso de agroquímicos nas culturas da cana-de-açúcar e na citricultura sobre as unidades aquíferas porosas e livres, como é o caso do Aquífero Aluvionar, Botucatu e Pirambóia.

- Tornar obrigatória a proteção territorial das áreas do aquífero Aluvionar, os quais estão dispostos nas áreas de fundo de vales e que, normalmente, possui conexão com a zona saturada. A proteção da vegetação nativa nessas áreas servirá como filtro natural destinado a conter os sedimentos e a poluição difusa carreada juntamente com o escoamento superficial, principalmente quando essas planícies aluviais são circundadas pelo cultivo da cana e de citrus. Estudos mostrando a importâncias dessas zonas de 'amortecimento' podem ser comprovados em Attanasio et al. (2013), Schilling e Jacobson (2014), Tanaka et al. (2016), Tromboni e Dodds (2017), Maello et al. (2018), Valera et al. (2019), Rocha et al. (2019) e Guidotti et al. (2020).

De modo a tornar a legislação municipal mais protetiva do que a Norma Técnica P4.231 (CETESB, 2014), que permite a aplicação de vinhaça em aquíferos livres (mais suscetíveis à contaminação) com profundidade do nível d'água de no mínimo 1,5m, deve ser impedido o uso de agrotóxicos e da fertirrigação nos domínios do aquífero Aluvionar (poroso e livre), pois representam potenciais fontes de contaminação química e orgânica.

Formar um cadastro único de imóveis rurais de modo a subsidiar, em escala municipal, o acompanhamento das áreas de reserva legal de preservação permanente de acordo com a legislação.

A fim de intensificar a proteção das áreas com potenciais de contaminação mais elevados, deve ser implantado o Pagamento por Serviços Ambientais (PSA) aos produtores rurais que conservarem suas nascentes revestidas por vegetação arbórea, nos moldes do "Programa Conservador das Águas", implantado no município de Extrema, MG (JARDIM; BURSZTYN, 2015). 


\section{CONSIDERAÇÕES FINAIS}

A bacia hidrográfica do Rio Claro apresentou elevado índice de potencial de contaminação de aquíferos para o período analisado. Em 1994 as classes de potencial de contaminação alto e muito alto abrangeram $46,1 \%$ da área da bacia enquanto que em 2014, esse percentual aumentou para $48,6 \%$.

Tal representatividade na bacia se deve notadamente as características hidrogeológicas da área que apresenta dominantemente unidades aquíferas porosas, livres e parcialmente livres, em unidades litoestratigráficas constituídas dominantemente por arenitos da bacia sedimentar do Paraná. Concomitantemente a tal condição de subsuperfície, a ocorrência de materiais inconsolidados de textura arenosa, com altos coeficientes de permeabilidade em áreas de baixa declividade do terreno e usos do solo destinados à atividade agrícola, principalmente a cana-de-açúcar, foram determinantes para elevar o grau de potencial de contaminação das águas subterrâneas.

Quando considerados os impactos da variação do uso e cobertura da terra sobre o potencial de contaminação, constatou-se que a intercalação entre o cultivo da cana-de-açúcar e solo exposto (preparado para o cultivo) foi fundamental para que se mantivesse o elevado potencial de contaminação dos aquíferos. Desta forma, é patente a necessidade de adoção de práticas conservacionistas no cultivo de cana, especialmente no período entressafras, para minimizar os impactos ambientais negativos desta cultura.

\section{AGRADECIMENTOS}

Os autores agradecem a Fundação de Amparo à Pesquisa do Estado de São Paulo (FAPESP) Processo 2013/03699-5, ao Conselho Nacional de Desenvolvimento Científico (CNPq) Processo 443802/2014-9 e a Coordenação de Aperfeiçoamento de Pessoal de Nível Superior (CAPES) Código de Financiamento 001, pelos recursos financeiros que tornaram viável o desenvolvimento deste trabalho.

\section{REFERÊNCIAS}

AGUIAR, A. D. C. Mapeamento Geotécnico da Folha de Conchal - SP: Escala 1:50.000. Dissertação de mestrado. EESC-USP, São Carlos, $102 p, 1995$.

ALLER, L. et al. DRASTIC: A Standardized System for Evaluating Ground Water Pollution Potential Using Hydro-geological Settings. 600. EPA, p. 622 (2-87-035), 1987.

ALLOUCHE, N. et al. A global risk approach to assessing groundwater vulnerability. Environmental Modelling \& Software, v. 88, p. 168-182, 2017. https://doi.org/10.1016/j.envsoft.2016.11.023

ATTANASIO, C. M. et al. A importância das áreas ripárias para a sustentabilidade hidrológica do uso da terra em microbacias hidrográficas. Bragantia, v. 71, n.4, 2013. https://doi.org/10.1590/S000687052013005000001

BORCHARDT, M. A. et al. Incidence of enteric viruses in groundwater from household wells in Wisconsin. Applied and Environmental Microbiology, v. 69, n. 2, p. 1172-1180, 2003. https://doi.org/10.1128/AEM.69.2.1172-1180.2003

BRASIL. Lei $\mathbf{n}^{\circ}$ 4.771, de 15 de setembro de 1965 . Institui o novo Código Florestal. Disponível em: <http://www.planalto.gov.br/ccivil_03/leis/14771.h tm>. Acesso em: 16 jul. 2020.

BRASIL. Lei $n^{\circ}$ 11.428, de 22 de dezembro de 2006. Dispõe sobre a utilização e proteção da vegetação nativa do Bioma Mata Atlântica, e dá outras providências. Disponível em:<http://www.planalto.gov.br/ccivil_03/_Ato200 4-2006/2006/Lei/L11428.htm>. Acesso em: 16 jul. 2020.

BRASIL. Lei $\mathrm{n}^{\mathbf{0}}$ 12.165, de 25 de maio de 2012. Dispõe sobre a proteção da vegetação nativa; altera as Leis $\mathrm{n}^{\circ} \mathrm{s} 6.938$, de 31 de agosto de 1981, 9.393, de 19 de dezembro de 1996, e 11.428, de 22 de dezembro de 2006; revoga as Leis $\mathrm{n}^{\circ} \mathrm{s} 4.771$, de 15 de setembro de 1965 , e 7.754 , de 14 de abril de 1989, e a Medida Provisória n ${ }^{\circ}$ 2.166-67, de 24 de agosto de 2001; e dá outras providências. Disponível em: <http://www.planalto.gov.br/ccivil_03/_ato20112014/2012/lei/112651.htm>. Acesso em: 16 jul. 2020.

BROLLO, M. J. Mapeamento Geotécnico da Folha de Araras - SP. Dissertação de mestrado. EESC-USP, São Carlos, 96p, 1991.

CANÇADO, C. J. et al. Estudo da vulnerabilidade de contaminação de aquíferos por pesticidas no município de Descalvado (Brasil). Anais do $11^{\circ}$. Congresso Nacional de Geotecnia, vol.4, p.277-284, 2008. Coimbra (Portugal).

CETESB - Companhia Ambiental do Estado de São Paulo. Norma Técnica P4.231: Vinhaça Critérios e procedimentos para aplicação no solo agrícola. 3 ed., 15 p. 2014 . Disponível em: $<$ http://www.ibra.com.br/wp- 
content/uploads/2015/02/p4_231_vinhaca_revisad a.pdf $>$. Acesso em: 16 de agosto de 2019.

COSTA, C. W. et al. Potential for aquifer contamination of anthropogenic activity in the recharge area of the Guarani Aquifer System, southeast of Brazil. Groundwater for Sustainable Development, v. 8, p. 10-23, 2019. https://doi.org/10.1016/j.gsd.2018.08.007

COSTA, C. W. et al. Potencial de contaminação de aquíferos por atividades antrópicas da Bacia do Ribeirão do Meio - Município de Leme - SP. Revista Brasileira de Recursos Hídricos, v. 20, n. $1, \quad$ p. 218-225, 2015b. https://doi.org/10.21168/rbrh.v20n1.p218-225

COSTA, C. W.; LORANDI, R.; DUPAS, F. A. Legislação municipal e a proteção das áreas de recarga em mananciais urbanos: São Carlos, SP. In: 1th Congresso Novos Direitos cidades em crise, São Carlos, p. 175-182, 2015a.

DAEE-IG-IPT-CPRM - Departamento de Águas e Energia Elétrica - Instituto Geológico - Instituto de Pesquisas Tecnológicas do Estado de São Paulo - Serviço Geológico do Brasil. Mapa de águas subterrâneas do Estado de São Paulo: escala 1:1.000.000: nota explicativa / [coordenação geral Gerôncio Rocha]. - São Paulo: 3v. 119p. 2005.

EASTMAN, J.R. Idrisi Selva: manual version 17. Worcester, MA: Clark University, 2012.

ESRI (Environmental Systems Research Institute). ArcGIS for the desktop 10.2. (2013).

FEITOSA, F.A. Hidrogeologia: conceitos e aplicações. Organização e coordenação científica: Fernando A.C. Feitosa et al. $3^{\mathrm{a}}$. Ed. rev. e ampl. Rio de Janeiro: CPRM: LABHID, 812p, 2008.

FOSTER, S. S.D. Fundamental concepts in aquifer vulnerability, pollution risk and protection strategy. [W:] van Duijvenboden W., van Waegeningh H. G [Red.] Vulnerability of Soil 872 P. WACHNIEW ET AL. and Groundwater to Pollutants. TNO Comm. on Hydro. Research. Hague, Proc. and Inform., 38, 69-86, 1987.

FOSTER, S; HIRATA, R; ANDREO, B. The aquifer pollution vulnerability concept: aid or impediment in promoting groundwater protection? Hydrogeology Journal, v. 21, n. 7, p. 1389-1392, 2013. https://doi.org/10.1007/s10040-013-1019-7

GANDY, C.J.; SMITH, J.W.N.; JARVIS. A.P. Attenuation of mining-derived pollutants in the hyporheic zone: a review. Science of the Total Environment, v. 373 n. 2-3, p. 435-446, 2007. https://doi.org/10.1016/j.scitotenv.2006.11.004

GORELICK, S. M.; ZHENG, C. Global change and the groundwater management challenge, Water Resour. Res. v. 51, n 5, p. 3031-3051, 2015. https://doi.org/10.1002/2014WR016825

GUIDOTTI, V. et al. Changes in Brazil's Forest Code can erode the potential of riparian buffers to supply watershed services. Land Use Policy, [s. 1.], 2020. https://doi.org/10.1016/j.landusepol.2020.104511

HUONG, H. T. L.; PATHIRANA, A. Urbanization and climate change impacts on future urban flooding in Can Tho city, Vietnam. Hydrology and Earth System Sciences, Goettingen, v.17, n.1, p. 379-
394, 2013. https://doi.org/10.5194/hess-17-3792013

IBGE - Instituto Brasileiro de Geografia e Estatística. Folhas Topográficas SF-23-V-C-IV-4, SF-23-VC-V-1 e SF-23-V-C-V-3. Escala 1:50.000. 1972.

IBGE - Instituto Brasileiro de Geografia e Estatística. Resolução $N^{\mathbf{0}}$ 1/2005. Estabelece o Sistema de Referência Geocêntrico para as Américas (SIRGAS). Brasília, Brasil.

IG - Instituto Geológico. Mapas Geológicos - Folha Descalvado (SF-23-V-C-IV-4) (1984), Folha Piraçununga (SF-23-V-C-V-3) (1981a), Folha Santa Rita do Passa-Quatro (SF-23-V-C-V-1) (1981b). Escala 1:50.000. São Paulo, 1984.

IRITANI, M. A. et al. Proposta de classificação das fontes potenciais de contaminação da água subterrânea. Revista do Instituto Geológico, v. 34, n. $2, \quad$ p. $1-26$, 2013.https://doi.org/10.5935/0100929X.20130006

JARDIM, M, H.; BURSZTYN, M. A. Pagamento por serviços ambientais na gestão de recursos hídricos: o caso de Extrema (MG). Eng Sanit Ambient, v. 20, n. 3, p. 353-360, 2015. https://doi.org/10.1590/S141341522015020000106299

JOHANSSON, P.; HIRATA, R. Rating of groundwater contamination sources. In: A. Zaporozec (ed.) Groundwater contamination inventory. A methodological guide. (2004). IHP-VI, Series on Groundwater, Paris, UNESCO, 2, p. 63-74, 2004.

KHOSRAVI, K. et al. A comparison study of DRASTIC methods with various objective methods for groundwater vulnerability assessment. Science of the Total Environment, v. 642, p.1032-1049, 2018. https://doi.org/10.1016/j.scitotenv.2018.06.130

KÖPPEN, W. Climatologia. México: Fondo de Cultura Econômica, 1948, 478 p.

LOLLO, J. A. Mapeamento Geotécnico da Folha de Leme - SP. Dissertação de mestrado. EESCUSP, São Carlos, 86p, 1991.

LORANDI, R.; LOLLO, J. A. Zoneamento Geoambiental Analítico da Bacia do Rio Claro (SP) na escala 1:50.000. Relatório Científico Final - Processo 2013/03699-5, FAPESP, 113p. 2016.

LORANDI, R.; LOLLO, J. A.; GUERRERO, J. V. R. Carta de unidades aquíferas aplicada ao zoneamento (geo)ambiental-Estudo de caso na bacia hidrográfica do Rio Claro (SP). In: 140. Congresso Nacional de Geotecnia, Covilhã. Atas do 14o. Congresso Nacional de Geotecnia. Lisboa - Portugal: Sociedade Portuguesa de Geotecnia, 2014. v. 1. p. 1-10, 2014.

LOURENCETTI, C. et al. Contaminação de águas subterrâneas por pesticidas: avaliação preliminar. Revista Química Nova. v. 30, nº. 3, p. 688-694, 2007. https://doi.org/10.1590/S010040422007000300031

MACHIWAL, D. et al. A review of GIS-integrated statistical techniques for groundwater quality evaluation and protection. Environmental Earth Sciences, v. 77, $\mathrm{n}^{\circ} . \quad 19,2018$. https://doi.org/10.1007/s12665-018-7872-x 
MAHVI, A.H. et al. Agricultural activities impact on groundwater nitrate pollution. International Journal of Environmental Science and Technology, v. 2, n. 1, p. 41-47, 2005. https://doi.org/10.1007/BF03325856

MARANGON, F. et al. Land use and groudwater resourses potential vulnerability to contamination. Agriculture \& Forestry, v. 63, p. 211-222, 2017. https://doi.org/10.17707/AgricultForest.63.1.25

MASSOLI, M. Geologia do Município de Santa Rita do Passa Quatro, SP. Revista do Instituto Geológico, v. 2, n. 2, p. 35-45, 1981.

MELLO, K. De. et al. Effects of land use and land cover on water quality of low-order streams in Southeastern Brazil: Watershed versus riparian zone. Catena, [s. l.], v. 167, n. April, p. 130-138, 2018. https://doi.org/10.1016/j.catena.2018.04.027

MELO, M. S. A. Formação Rio Claro e depósitos associados: sedimentação neocenozóica na Depressão Periférica Paulista. São Paulo. 144p., 1995. (Tese de Doutorado, IG-USP).

MENEZES, J. P. C. et al. Correlação entre uso da terra e qualidade da água subterrânea. Revista de Engenharia Sanitária e Ambiental. v.19, n. 2, p. 173-186. abr/jun, 2014.

MILLENNIUM ECOSYSTEM ASSESSMENT. Ecosystems and Human Well-Being: Synthesis (Island Press, Washington, DC), 2005. Disponível em:

$<$ http://www.millenniumassessment.org/documen ts/document.356.aspx.pdf>. Acesso em: $16 \mathrm{de}$ agosto de 2019.

MORAES, M. E. B. et al. A legislação ambiental da bacia do rio Claro, São Paulo. In: Moraes, M. E. B.; Lorandi, R. (organizadores). Métodos e técnicas de pesquisa em bacias hidrográficas. Ilhéus, BA: Editus, 2016. Cap. 13. p. 1-18. Disponível em: <http://books.scielo.org/id/4wbr2>. Acesso em: 16 de julho de 2020.

MORAES, M. E. B. et al. Conservation Of Groundwater Recharge: A Methodological Proposal. In: Bilibio, Carolina; Hensel, Oliver; Selbach, Jeferson. (Org.). Sustainable water management in the tropics and subtropics and case studies in Brazil. 1ed. Bagé (RS): Fundação Universidade Federal do Pampa, v. 1, p. 659-680, 2011.

MORAN, M. J.; ZOGORSKI, J. S.; SQUILLACE, P. J. MTBE and gasoline hydrocarbons in ground water of the United States. Ground Water, v. 43, n. 4, p. 615-627, 2005. https://doi.org/10.1111/j.17456584.2005.0113.x

ONATE-VALDIVIESO, F.; SENDRA, J. B. Application of GIS and remote sensing techniques in generation of land use scenarios for hydrological modeling. Journal of Hydrology, Amsterdam, v. 395, n. 3-4, p. 256-263, dez. 2010. https://doi.org/10.1016/j.jhydrol.2010.10.033

OSENBRUCK, K. et al. Sources and transport of selected organic micropollutants in urban groundwater underlying the city of Halle (Saale), Germany. Water Research, v. 41, n. 15, p. 3259-
3270 , 2007. https://doi.org/10.1016/j.watres.2007.05.014

PIGA, F. G. et al. Multi-criteria potential groundwater contamination and human activities: Araras watershed, Brazil. Revista Brasileira de Recursos Hídricos, v. 22, p. e56, 2017. https://doi.org/10.1590/2318-0331.0217170052

POWELL, K. L. et al. Microbial contamination of two urban sandstone aquifers in the UK. Water Research, v. 37, p. 339-352, 2003. https://doi.org/10.1016/S0043-1354(02)00280-4

RAVENGA, C. Developing indicators of ecosystem condition using geographic information systems and remote sensing. Regional Environmental Change, v. 5, n. 4, p. 205-214, 2005. https://doi.org/10.1007/s10113-004-0085-8

ROCHA, C. H. B. Geomática na prática. Curitiba: Editora CRV, 2019, 290p, ISBN 978-85-444-31139, DOI 10.24824/978854443113.9.

ROCHA, C. H. B.; FREITAS, F. A.; CASQUIN, A. P. Conflitos de uso da terra nas APPs hídricas de manancial da Zona da Mata mineira, Brasil. Boletim Goiano de Geografia, v. 39, p. 1-22, 2019. https://doi.org/10.5216/bgg.v39.50021

ROSS, J. L. S.; MOROZ, I. C. Mapa geomorfológico do Estado de São Paulo. Escala: 1:500.000. São Paulo - FFLCH/USP-IPT-FAPESP, 1997.

SANTA RITA DO PASSA QUATRO. Lei $\mathbf{n}^{\mathbf{2}} \mathbf{2 . 6 6 7}$, de 10 de outubro de 2006. Institui o Plano Diretor do município de, estabelece diretrizes gerais da política do desenvolvimento municipal e dá outras providências, 2006. Disponível em: $<$ https://santaritadopassaquatro.sp.gov.br/planod iretor/PLANO\%20DIRETOR.pdf?phpMyAdmin=1 9385d865449847d0eecca2d72e7fdd8>. Acesso em: 16 de julho de 2020.

SÃO PAULO (Estado). Decreto 32.955, de 7 de fevereiro de 1991. Regulamenta a Lei 6.134, de 2 de junho de 1988 que dispõe sobre a preservação dos depósitos naturais de águas subterrâneas do Estado de São Paulo, e dá outras providências. Disponível

em: <https://www.al.sp.gov.br/repositorio/legislacao/d ecreto/1991/decreto-32955-07.02.1991.html>. Acesso em: 16 de julho de 2020.

SÃO PAULO (Estado). Inventário Florestal da Vegetação Natural do Estado de São Paulo, Instituto Florestal do Estado de São Paulo, 2009. Disponível em: <https://www.infraestruturameioambiente.sp.gov .br/institutoflorestal/2005/03/inventario-florestalda-vegetacao-natural-do-estado-de-sao-paulo/>. Acesso em: 16 de julho de 2020.

SCHEWE, J. et al. Multimodel assessment of water scarcity under climate change. Proceedings of the National Academy of Sciences of the United States, v. 111, n. 9, p. 3245-3250, 2014. https://doi.org/10.1073/pnas.1222460110. PMid:24344289 PMCid:PMC3948304

SCHILLING, K. E.; JACOBSON, P. Effectiveness of natural riparian buffers to reduce subsurface nutrient losses to incised streams. Catena, [s. 1.], v. 114, p. 140-148, 2014. http://dx.doi.org/10.1016/j.catena.2013.11.005 
TANAKA, M. O. et al. Influence of watershed land use and riparian characteristics on biological indicators of stream water quality in southeastern Brazil. Agriculture, Ecosystems and Environment, [s. 1.], v. 216, p. 333-339, 2016. http://dx.doi.org/10.1016/j.agee.2015.10.016

TAVANTI, D. R. et al. Estudo da vulnerabilidade de contaminação de aquífero por agrotóxicos, na região de Descalvado e Analândia (SP). Revista Brasileira de Recursos Hídricos, v. 14, $\mathrm{n}^{\circ} .1$, p. 53-61, 2009. https://doi.org/10.21168/rbrh.v14n1.p53-61

TROMBONI, F.; DODDS, W. K. Relationships Between Land Use and Stream Nutrient Concentrations in a Highly Urbanized Tropical Region of Brazil: Thresholds and Riparian Zones. Environmental Management, [s. l.], v. $60, \quad$ n. $1, \quad$ p. $30-40, \quad 2017$. http://dx.doi.org/10.1007/s00267-017-0858-8

TUNDISI, J. G.; MATSUMURA-TUNDISI, T.; MATSUMURA-TUNDISI, J. E. Conservação e uso sustentável de recursos hídricos. In: Barbosa, F.A. Ângulos da água: desafios da integração. Belo Horizonte: Editora UFMG, p. 83-157, 2008.

TUNDISI, J.G.; MATSUMURA-TUNDISI, T.M. Impactos potenciais das alterações do Código Florestal nos recursos hídricos. Biota Neotropica. v. 10, n. 4, p. 67-76, 2010. https://doi.org/10.1590/S167606032010000400010

UNITED NATIONS - UNITED NATIONS WORLD WATER ASSESSMENT PROGRAMME - WWAP. The United Nations World Water Development Report 2015: Water for a Sustainable World. Paris, UNESCO, 2015. Disponível em: $<$ http://www.unesco.org/new/en/naturalsciences/environment/water/wwap/wwdr/2015water-for-a-sustainable-world/>. Acesso em: $16 \mathrm{de}$ julho de 2020.

USGS - United States Geological Survey. Imagens LANDSAT_5 e LANDSAT_8. órbita/ponto 220/75. Disponível em: <http://earthexplorer.usgs.gov/> Acesso em: 20/02/2016.

VALERA, C. A. et al. The buffer capacity of riparian vegetation to control water quality in anthropogenic catchments from a legally protected area: A critical view over the Brazilian new forest code. Water, v. 11, n. 3, p. 549, 2019. https://doi.org/10.3390/w11030549

VARNIER, C.; HIRATA, R. Contaminação da água subterrânea por nitrato no Parque Ecológico do Tietê - São Paulo, Brasil. Rev. Águas $\begin{array}{lll}\text { Subterrâneas. } \quad \mathrm{n}^{\circ} & \text { 16/Maio, } 2002 .\end{array}$ https://doi.org/10.14295/ras.v16i1.1303

WACHNIEW, P. et al. Toward operational methods for the assessment of intrinsic groundwater vulnerability: A review. Critical Reviews in Environmental Science And Technology. v. 46, $\quad$ p. $\quad 827-884, \quad 2016$. https://doi.org/10.1080/10643389.2016.1160816

World Health Organization and United Nations Children's Fund Joint Monitoring Programme for Water Supply and Sanitation (JMP). (2008.).
Progress on Drinking Water and Sanitation: Special Focus on Sanitation. UNICEF, New York and WHO, Geneva <http://www.bvsde.paho.org/bvsaca/fulltext/progr ess.pdf>. Acesso em 20 de julho de 2019. 